\title{
TINEL'S WITH TOURNIQUET TEST FOR THE DIAGNOSIS OF CARPAL TUNNEL SYNDROME- A NEW PROVOCATIVE CLINICAL TEST
}

\author{
A. N. Sadanandan ${ }^{1}$, P. Rijesh ${ }^{2}$ \\ ${ }^{1}$ Associate Professor, Department of Orthopaedics, Malabar Medical College Hospital and Research Centre, Modakkallur, Atholi, \\ Kozhikode. \\ ${ }^{2}$ Assistant Professor, Department of Orthopaedics, Malabar Medical College Hospital and Research Centre, Modakkallur, Atholi, \\ Kozhikode.
}

\section{ABSTRACT}

\section{BACKGROUND}

Commonly used clinical tests to diagnose Carpal Tunnel Syndrome (CTS) are provocative tests, which involves compression of median nerve at carpal tunnel. Some of these tests are Phalen's test, Durkan's test and Tinel's sign.

\section{MATERIALS AND METHODS}

This was a descriptive study. Sample size was taken conveniently. 134 consecutive hands (in patients with symptoms suggestive of CTS) were tested with a new clinical test combining Tourniquet test with Tinel's sign (T, TT, TTT) to increase the sensitivity and specificity of both of these tests if done separately. Out of these hands, seventy-one (n) were included for which all data were available. Attempts were made to grade the carpal tunnel syndrome based on severity, similar to grading done for nerve conduction study report. The results obtained were analysed and compared with that of nerve conduction study for carpal tunnel syndrome.

\section{RESULTS}

The statistical methods used were chi square test $(2 * 6$ cross contingency tabulation), Pearson Correlation Coefficient analysis. The new clinical test (Tinel's, Tourniquet, Tinel's with tourniquet- T, TT, TTT) was correlated with the Nerve Conduction Study (NCS) for carpal tunnel syndrome. Pearson correlation coefficient was calculated for both the tests (new test and NCS), which showed positive correlation when ' $n$ ' was analysed $(0.2339, \mathrm{p}<0.05)$. When the tests were analysed with two grades considered up or down, there was a $66.2 \%$ correlation. Chi square test $(2 * 6$ tabulation) returned significant $p$ value.

\section{CONCLUSION}

The new clinical test for carpal tunnel syndrome- Tinel's with Tourniquet test (T, TT, TTT) increases the sensitivity of Tinel's test, which is usually considered a clinical test with high specificity. It also helped to assess the severity of the disease, thus helping in decision-making regarding further treatment. Even though the analysis returned a positive correlation, bigger sample size is required to further validate this new test.

\section{KEYWORDS}

Carpal Tunnel Syndrome, CTS, Tinel's Test, Tinel's with Tourniquet Test, TTT Test, Nerve Conduction Study, NCS.

HOW TO CITE THIS ARTICLE: Sadanandan AN, Rijesh P. Tinel's with tourniquet test for the diagnosis of carpal tunnel syndrome- a new provocative clinical test. J. Evolution Med. Dent. Sci. 2017;6(63):4572-4575, DOI: 10.14260/Jemds/2017/989

\section{BACKGROUND}

Carpal Tunnel Syndrome is a disorder caused by compression of median nerve at wrist causing numbness, tingling and sometimes weakness of muscle supplied by it in hand. Many clinical tests have been used for the diagnosis of carpal tunnel syndrome. Most of these are provocative tests which involves compression of median nerve at carpal tunnel and the examiner assesses the reappearance of symptoms or exacerbation of symptoms in the lateral three fingers.

The clinical diagnosis of carpal tunnel syndrome is usually made based on history, physical signs and provocative tests. The sensitivities of Phalen's wrist flexion tests and Tinel's percussion tests vary from $44 \%$ to $75 \%$ with

Financial or Other, Competing Interest: None.

Submission 17-07-2017, Peer Review 31-07-2017,

Acceptance 01-08-2017, Published 07-08-2017.

Corresponding Author:

Dr. P. Rijesh,

\#34/733, Pottangadi,

PO Civil Station,

Kozhikode-673020, Kerala.

E-mail:drrijesh@gmail.com

DOI: 10.14260/jemds/2017/989

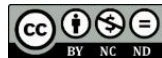

specificities of $70 \%$ to $100 \%$.[1] Specificity and sensitivity of Tourniquet test in one study was $65 \%$ and $60 \%$ respectively.[2]

We hypothesised that combining tourniquet test with percussion test (Tinel's Test) increases the specificity and sensitivity of diagnosis of carpal tunnel. This shall be referred to as Tinel's with Tourniquet test (TTT) here.

\section{MATERIALS AND METHODS}

\section{The aims of this study were-}

1. To study the effectiveness of the new test in the diagnosis of carpal tunnel syndrome.

2. To compare the effectiveness of diagnosis of new test with that of nerve conduction study.

This study was descriptive in design. All the clinical tests were performed by one examiner (first author), who has 28 years of experience in Orthopaedics after attaining the postgraduate degree from Government Medical College in India.

All the patients who came with upper limb pain on one side or both sides with numbness in the hand and had 
undergone this test and willing to participate in this study were included in this study.

A sample size was taken conveniently. Out of 134 hands for which data were collected, 63 were excluded and remaining 71 were included in the study.

First a Tinel's sign was performed as described in the textbook with percussion on the distal forearm and wrist along the course of median nerve from proximal to distal and noted for appearance of symptoms/ exacerbation of symptoms or appearance of pins and tingles sensation over the palm in the median nerve sensory distribution. If the Tinel's sign was positive, the patient was designated to have severe Carpal Tunnel Syndrome and no further tests were carried. If the Tinel's sign was negative, further tests were carried out as mentioned (TT and TTT) below.

The BP cuff of sphygmomanometer was then applied on the arm to be tested and then the BP was recorded. The cuff was again inflated to $5-10 \mathrm{mmHg}$, more than the systolic pressure. If the symptoms appeared immediately after (TT), it would be considered as severe carpal tunnel syndrome. The percussion was started over median nerve at wrist (over transverse carpal ligament just medial to palmaris longus tendon) at the rate of one 'beat' per second and patient was examined for same sensations as mentioned above and the beat at which symptoms appeared was noted. The patient for which symptoms appeared before $10^{\text {th }}$ beat was designated as moderate-to-severe carpal tunnel syndrome, between $11^{\text {th }}$ and $20^{\text {th }}$ was designated to have moderate carpal tunnel syndrome. Those who had symptoms between $2^{1 \text { st }}$ and $30^{\text {th }}$ beats were considered mild-to-moderate and between $31^{\text {st }}$ and $50^{\text {th }}$ were considered as mild carpal tunnel syndrome. Those patients who did not have any symptoms on percussing for 50 times after application of 'tourniquet,' i.e. BP cuff were designated as normal. Phalen's test and Durkan's test were also done for these patients. These patients were then advised nerve conduction study of median nerve of both upper limbs and review with reports. Some patients lost to followup, hence the data of NCS could not be obtained. These patients were excluded from the study. Other exclusion criteria were-

1. Patients with h/o trauma around right wrist requiring plaster application or surgery.

2. Clinical evidence of space occupying lesions in the carpal tunnel (pre-operatively/ post-operatively).

\section{RESULTS}

\section{Statistical Analysis}

The data collected were analysed after compiling them in MS Excel spreadsheet (Microsoft $\AA$ Excel ${ }^{\circledR}$ for Mac 2011 Version 14.6.2). Analysis of mean and calculation of ' $n$ ' in each group were done with the same software. Chi square calculations were done with open source online. Chi square calculator is available at-

http://turner.faculty.swau.edu/mathematics/math241/ materials/contablecalc/. Pearson correlation coefficient was calculated in MS Excel as well as with another open source online PCC calculator (http://www.socscistatistics.com/ tests/ Pearson/ Default2.aspx).
Total number of hands which were studied was 134, of which only 71 hands were included in the study; others were excluded due to incomplete data (nerve conduction study). There were 62 females and 9 males.

The mean age of the group was 44.99 years, ranging from 64 years to 28 years.

Out of the hands examined, 38 were right and 33 were left.

Phalen's test and Durkan's test were done and results were recorded; 52 had Phalen's positive, while 19 were negative; 50 hands had positive Durkan's, while 21 had negative.

Tinel's test (T) was done for all patients and then for patients who had negative Tinel's were subjected to Tourniquet Test (TT) and those for whom symptoms did not appear were again subjected to Tinel's Test with Tourniquet (TTT). As described above, these tests were done in continuum and end point was either appearance of symptoms or $50^{\text {th }}$ beat with Tinel's with Tourniquet (TTT) even if symptoms did not appear. They were graded into six as severe, moderate-to-severe, moderate, mild-to-moderate, mild and normal. Out of 71, 43 were designated as having severe CTS, 8 had moderate-to-severe CTS, 2 had moderate CTS, 8 mild-to-moderate, 5 mild CTS and 5 were designated as normal.

NCS for median nerve was advised for these patients; 71 hands for which NCS reports could be collected were included for analysis; 31 hands had severe CTS, 13 had moderate-to-severe, 17 had moderate CTS, 1 had mild-tomoderate CTS, and 7 had mild CTS; 2 were reported as normal.

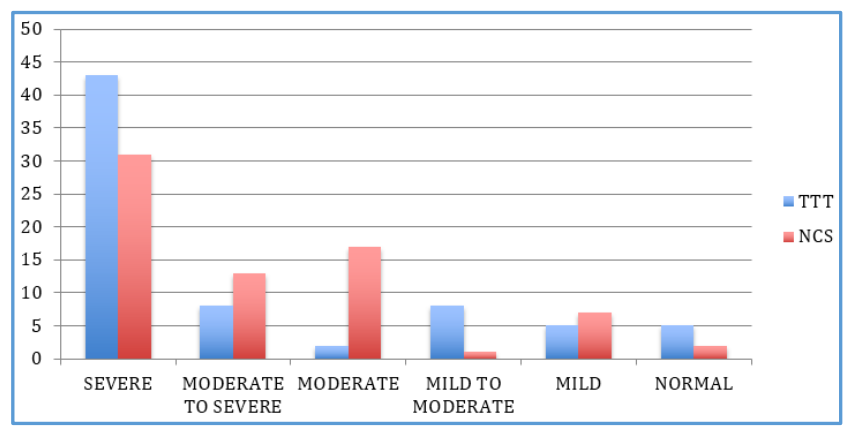

Figure 1. Distribution-X-Axis- Grades, Y-Axis- Number; Blue as New Test; Red as NCS

To assess the correlation of NCS and the new test, qualitative and quantitative analysis were done.

The Pearson Correlation Coefficient (PCC) is a measure of the linear correlation between two variables, where 1 is total positive linear correlation, 0 is no linear correlation and -1 is total negative linear correlation.

The PCC calculated for individual hands (71 pairs) was 0.2339 , which showed a positive correlation with significant $\mathrm{p}$ value $0.049621(<0.05)$. When the groups of grades $(6$ pairs) were analysed, Pearson coefficient was 0.7877 with significant $p$ value 0.062823 (with $p$ value $<0.10$ ).

If the grades from both groups (new test vs. NCS) were correlated keeping 1 or 2 grades up/down, 47 correlated (66.2\%), whereas 24 did not. 
The chi square test done as two-way contingency table for 6 pairs returned a significant ' $p$ ' value.

\begin{tabular}{|c|c|c|c|}
\hline & \multicolumn{2}{|c|}{ Chi Square TTT vs NCS for CTS } & \\
\hline & TTT & NCS & \\
\hline Severe & $\begin{array}{c}43 \\
37.00 \\
(0.97)\end{array}$ & $\begin{array}{c}31 \\
37.00 \\
(0.97)\end{array}$ & 74 \\
\hline $\begin{array}{l}\text { Moderate-to- } \\
\text { Severe }\end{array}$ & $\begin{array}{c}8 \\
10.50 \\
(0.60)\end{array}$ & $\begin{array}{c}13 \\
10.50 \\
(0.60)\end{array}$ & 21 \\
\hline Moderate & $\begin{array}{c}2 \\
9.50 \\
(5.92) \\
\end{array}$ & $\begin{array}{c}17 \\
9.50 \\
(5.92)\end{array}$ & 19 \\
\hline $\begin{array}{l}\text { Mild-to- } \\
\text { Moderate }\end{array}$ & $\begin{array}{c}8 \\
4.50 \\
(2.72)\end{array}$ & $\begin{array}{c}1 \\
4.50 \\
(2.72)\end{array}$ & 9 \\
\hline Mild & $\begin{array}{c}5 \\
6.00 \\
(0.17)\end{array}$ & $\begin{array}{c}7 \\
6.00 \\
(0.17)\end{array}$ & 12 \\
\hline Normal & $\begin{array}{c}5 \\
3.50 \\
(0.64)\end{array}$ & $\begin{array}{c}2 \\
3.50 \\
(0.64)\end{array}$ & 7 \\
\hline & 71 & 71 & 142 \\
\hline $\begin{array}{r}\text { Table 1. } \chi^{2} C \\
\chi^{2}=22.042, \\
\text { Expected } \\
\chi^{2} \mathrm{va}\end{array}$ & $\begin{array}{l}\text { ations }(T) \\
\chi^{2} / d f=4 \\
\text { s are disp } \\
\text { are displa }\end{array}$ & $\begin{array}{l}\text { ntingenc } \\
22.042) \\
\text { alic. Indi } \\
\text { rentheses }\end{array}$ & $\begin{array}{l}\text { able) } \\
0005 \\
\text { lal }\end{array}$ \\
\hline
\end{tabular}

The sensitivity of Tinel's sign in this study was $62.32 \%$, (43 true positives, 26 false negatives) and the specificity $100 \%$ ( 0 false positives, 2 true negative). The sensitivity increased to $95.65 \%$ with TTT ( 66 true positives and 3 false negatives), but specificity reduced to $50 \%$ (though False positive was only 1 and true negative was 1 ).

\section{DISCUSSION}

Though the symptoms of Carpal Tunnel Syndrome had been known as back as in mid-1800s, the definite description of the condition could only be done after World War II.[2] Learmonth in 1933 described two cases he operated in 1929, in which he divided flexor retinaculum for median neuropathy. ${ }^{[4]}$ Later in 1946, Cannon and Love published 38 cases of distal median neuropathy treated by surgical division of flexor retinaculum.[5] The source of the name Carpal Tunnel Syndrome is unclear. Kremer et al who in turn credited this to a 1949 personal communication by MJ McArdle, first used it in print in 1953. George Phalen in his classic papers in 1950,[6] 1951 and 1957 wrote about his clinical experience in many cases.

Understanding of pathophysiology of compressive neuropathy suggests ischaemic changes within the nerve caused by mechanical compression. These disturbances in the intraneural blood and oxygen flow in the perineural and intraneural regions of the nerve lead to irregularities in axonal transport and fibrosis of the nerve itself. The result is abnormal impulse generation, progressive conduction delay, and eventual axonal damage.[7]

Diagnosis of CTS is mostly clinical. The most common subjective symptom is "nocturnal acroparaesthesia,"[8] sometimes disturbing sleep. This paraesthesia may occur during day or may be triggered by certain positions or activities like sewing, driving, holding phone or a book for reading and may be resolved by changing the position of upper limb by shaking or massaging it. Patient's report reduced manual dexterity, because they frequently drop small objects which they cannot hold.

Many of our patients had similar complaints with increased numbness on holding the broom, while cleaning, holding on bus handrails and while working in kitchen. Some patients reported not able to hold utensils for long and dropping them.

The Tinel's sign involves percussion over the median nerve along from forearm to the wrist in proximal distal direction. It is positive when paraesthesias are elicited in the territory of nerve distribution. Kuschner et al noted that Tinel's sign alone is not sufficient to establish a diagnosis of CTS.[9] Phalen's test is done holding the wrist in maximal flexion for 60 seconds and if a sensation of numbness as well as paraesthesia occurs it is considered. Durkan's test involves compression of median nerve in the territory of carpal tunnel for 30 seconds and evaluate onset of paraesthesia. Durkan reported this test as positive in 87\%.[10] Williams reported this positive in $100 \%$ of patients.[11] Gilliat and Wilson described tourniquet test in 1953. External pressures of 20 to $30 \mathrm{mmHg}$ have been shown to impair venous blood flow and retard axonal transport, while pressures of $130-150 \mathrm{mmHg}$ cause a conduction block.[1]

Several other diagnostic tests are being used which includes Weber's two-point discrimination test, Van Frey's pressure test with Semmes-Weinstein's monofilaments and assessment of Abductor Pollicis Brevis if present. Different studies have assessed the sensitivity and specificity of diagnosis of CTS. The table below gives the interpretation of positive results in different provocative tests.[12,13,1]

\begin{tabular}{|c|c|c|}
\hline Tests & Sensitivity & Specificity \\
\hline Tinel's test & 0.41 & 0.90 \\
\hline Phalen's test & 0.59 & 0.83 \\
\hline Durkan's test & 0.42 & 0.99 \\
\hline Reverse Phalen's test & 0.55 & 0.96 \\
\hline Tourniquet's test[1] & 0.65 & 0.60 \\
\hline
\end{tabular}

Electrodiagnostic examination in CTS shows involvement of motor, sensory fibres or both. It also helps delineate physiologic basis (axon loss, demyelination) and severity of lesions (degree of axonal loss, the continuity of axons).[12] It can be of some value in litigation purpose should the intervention be less than satisfactory for the patient.

\section{The Diagnostic Criteria for CTS on Electrodiagnostic Study is as follows-}

- Evidence of sensory nerve fibre compression.

- Absent or delayed motor nerve SAP (>3.4 ms).

- Increased median-to-ulnar latency difference of the fourth finger SAP $(>0.5 \mathrm{~ms})$.

- Evidence of motor nerve fibre compression.

- Increased distal motor latency (>4.2 ms).

- Denervation signs in the abductor pollicis brevis muscle.

The pooled sensitivity and specificity of electrodiagnostic study using median sensory and mixed nerve conduction is around 0.85 and $0.98 .{ }^{[14]}$ Other methods of electrodiagnostic studies suggested sensitivities ranging from 0.56 to 0.85 and specificities ranging from 0.94 to 0.97 . 
As noted above though specificity of Tinel's sign is high, the sensitivity is not; hence, the author has attempted to increase the sensitivity also by adding tourniquet test and Tinel's with tourniquet test to the former to make a series of three tests in continuum. This also helped to assess the severity of CTS patients had. The results could be compared with NCS for correlation. The results suggest that there is significant $(\mathrm{p}<0.05)$ positive correlation between the two tests, (Pearson correlation coefficient 0.2339, ' $n$ ' being 71) but a greater number is required to assess its validity in a better way. When the tests were analysed for correlation based on groups (based on severity), significant PCC was noted at $0.7877(\mathrm{p}<0.10)$.

\section{CONCLUSION}

Carpal tunnel syndrome which is median neuropathy at carpal tunnel is a common condition with significant disability affecting activities of daily living in many patients. Most of the clinical diagnostic tests are provocative, evaluating the numbness or paraesthesia in the median nerve distribution, but it usually returns the results in Boolean data type, i.e. positive or negative. NCS helps evaluate the physiological basis and also severity of lesions.

The new test, namely Tinel's test followed by Tourniquet test and then Tinel's with Tourniquet test (T, TT, TTT) helped to increase the sensitivity of the Tinel's test, which is usually considered a test with high specificity. It also helped to assess the severity of the disease, thus helping in decision-making regarding further treatment. Even though the analysis returned a positive correlation, bigger sample size is required to further validate this new test.

\section{REFERENCES}

[1] Tetro AM, Evanoff BA, Hollstein SB, et al. A new provocative test for carpal tunnel syndrome. Assessment of wrist flexion and nerve compression. J Bone Joint Surg Br 1998;80(3):493-8.

[2] Gellman H, Gelberman RH, Tan AM, et al. Carpal tunnel syndrome. An evaluation of provocative tests. J Bone Joint Surg Am 1986;68(5)735-7.
[3] Amadio PC. History of carpal tunnel syndrome. In: Luchetti R, Amadio P. eds. Carpal tunnel syndrome. Springer-Verlag 2002:3-9.

[4] Learmonth JR. The principle of decompression in the treatment of certain diseases of peripheral nerves. Surg Clin North Am 1933;13:905-13.

[5] Cannon BW, Love JG. Tardy median palsy, median neuritis, median thenar neuritis amenable to surgery. Surgery 1946;20:210-6.

[6] Phalen GS, Gardner WJ, La Londe AA. Neuropathy of median nerve due to compression beneath the transverse carpal ligament. J Bone Joint Surg Am 1950;32A(1):109-12.

[7] Freeland AE, Tucci MA, Sud V. Ischemia-Reperfusion injury as a common etiology of "Idiopathic" carpal tunnel syndrome: biochemical and immunohistochemical evidence. In: Luchetti $\mathrm{R}$, Amadio P. eds. Carpal Tunnel Syndrome. Springer 2002:42-8.

[8] Ceruso M, Angeloni R, Lauri G, et al. Clinical diagnosis. In: Luchetti R, Amadio P. eds. Carpal Tunnel Syndrome. Springer 2002:42-8.

[9] Kuschner SH, Ebramzadeh E, Johnson D, et al. Tinel's sign and Phalen's test in carpal tunnel syndrome. Orthopaedics 1992;15(11):1297-302.

[10] Durkan JA. A new diagnostic test for carpal tunnel syndrome. J Bone Joint Surg Am 1991;73(4):535-8.

[11] Williams TM, Mackinnon SE, Novak CB, et al. Verification of the pressure provocative test in carpal tunnel syndrome. Ann Plast Surg 1992;29(1):8-11.

[12] Kotwal PP, Varshney MK. Carpal tunnel syndrome: current concepts. JIMSA 2011;24(1):21-5.

[13] Braun RM, Davidson K, Doehr S. Provocative testing in the diagnosis of dynamic carpal tunnel syndrome. J Hand Surg Am 1989;14(2 Pt1):195-7.

[14] Jablecki CK, Andary MT, Floeter MK, et al. Practice parameter: electrodiagnostic studies in carpal tunnel syndrome. Report of the American Association of Electrodiagnostic Medicine, American Academy of Neurology and the American Academy of Physical Medicine and Rehabilitation. Neurology 2002;58(11):1589-92. 